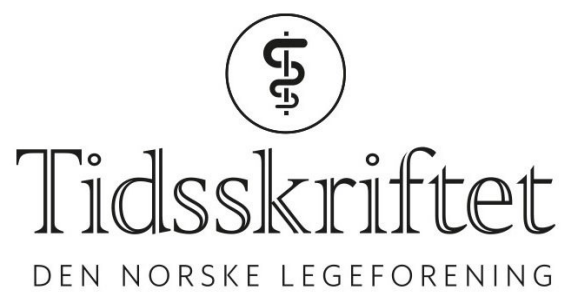

\title{
Hode for målgivende tilpasninger
}

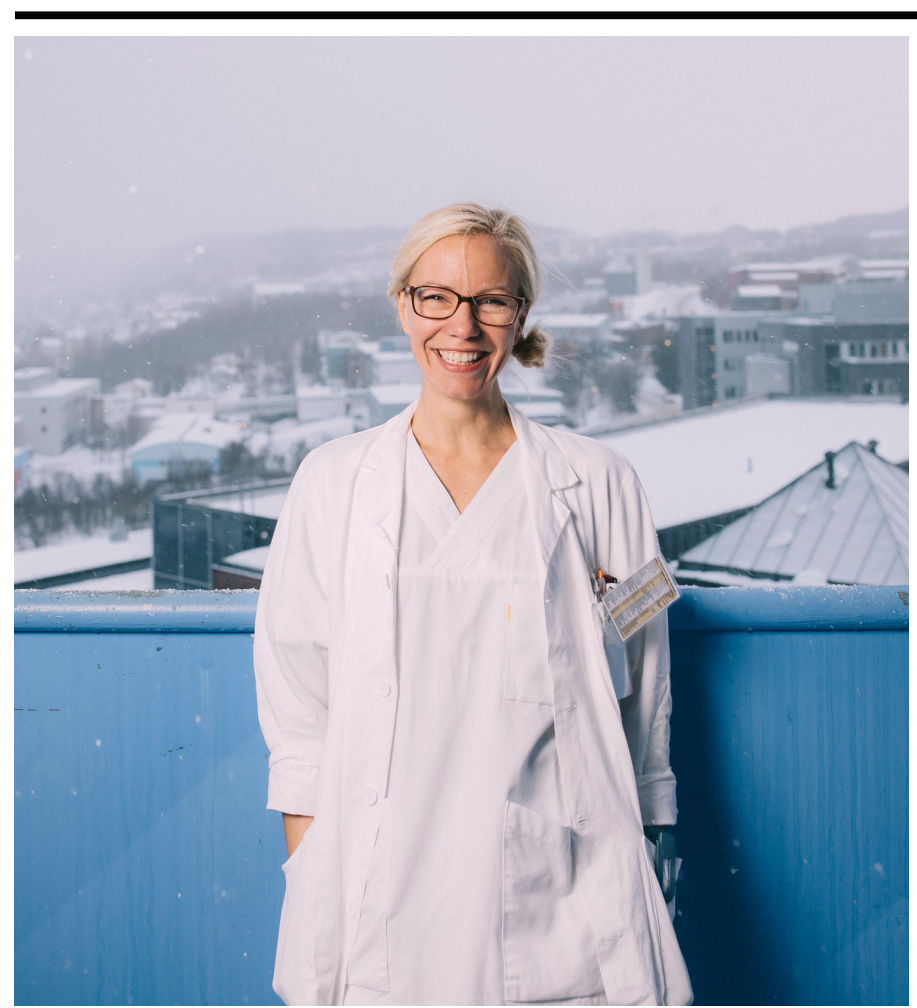

INTERVJU

\section{RUNE SKOGHEIM}

E-post: runeskogheim@hotmail.com

Hun er en kaptein på de plagedes lag og prøver å spille dem gode. Men hurtigheten sin, den får ikke Maja Wilhelmsen demonstrere i korridorene lenger. 


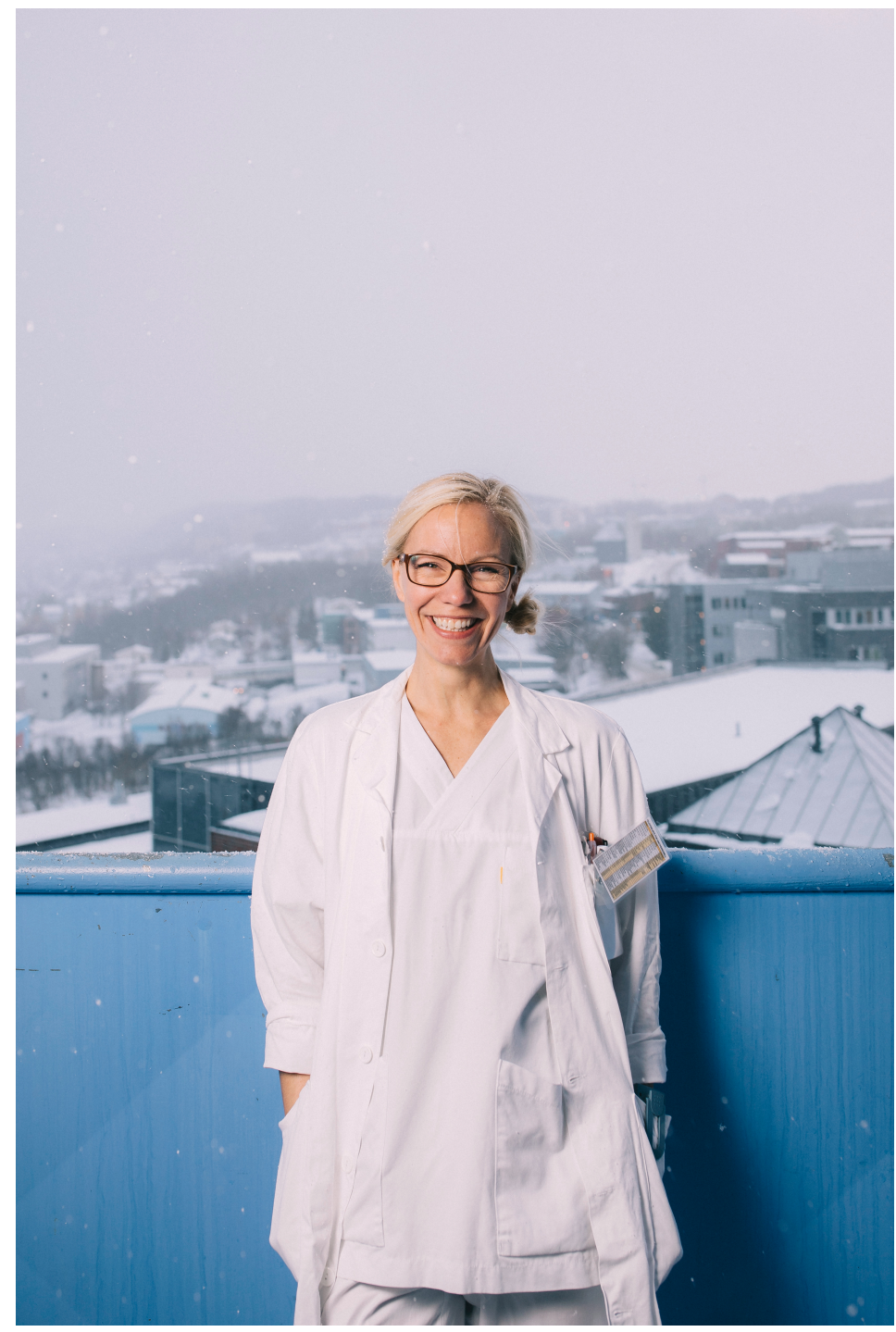

For noen uker siden fikk jeg mailsvar fra henne: «Hei! Tirsdag 31.10. er det Halloween og klokka 17 kommer 24 kids med foreldre hjem til meg for å spise likfingerpølser. Hva med mandag??» Det er lenge siden jeg har satt tennene i en god likfingerpølse, men jeg svelger skuffelsen i stedet.

Tromsø teppebombes av nysnø, mandagen er her, klokken er der, og bilen er borte. Jeg oppdager en form for hevelse i terrenget, og etter flere dype søk lykkes jeg å finne den begravde japaneren. Den må ha hatt en luftlomme der nede et sted, for lysene blinker på kommando, og ved første kompresjon hostes både sirkulasjon og forbrenning i gang.

Etter en kort ekspedisjon på det som inntil i går var kjent som den blå planeten, skimter jeg en liten skapning som synes å høre hjemme her. Godt kledd, godt skodd og med lua godt ned i øynene: «Heija! E det du som skal intervjue ho mamma?!»

\section{Å løfte i lag}

«Ho mamma» møter meg i døren. Rød overdel, blondt oppsatt hår, smarte briller og et skjerpet blikk. Hun er ikke særlig gammel og ikke særlig stor, likevel har hun en naturlig autoritet. Men hun er ikke stiv i stilen og vinker meg blidt innover i varmen.

\section{Maja Wilhelmsen}

Født i 1978, oppvokst i Troms

Grunnfag i kriminologi, Universitetet i Oslo, 1999-2000

Medisin profesjonsstudium, Universitetet i Tromsø, 2000-07

Turnustjeneste ved UNN Tromsø og på Andenes, 2007-09 
Fastlegevikar (50\%) ved Kaigata legekontor, Tromsø, 2009-13

Stipendiat (50\%) ved Universitetet i Troms $\emptyset$, Allmennmedisinsk forskningsenhet, 2009-13

Gjestestipendiat ved Melbourne University, Australia, 2013-14

Lege i spesialisering ved Fysikalsk- og rehabiliteringsmedisinsk avdeling, UNN Troms $\varnothing$,

2014-16

Ph.d., Universitetet i Tromsø, 2015

Arbeidsutvalg for regionalt nettverk CFS/ME, fra 2015

Konstituert overlege ved Fysikalsk- og rehabiliteringsmedisinsk avdeling, UNN Troms $\emptyset$,

2016

Styremedlem Norsk fysikalskmedisinsk forening, fra 2016

- Kom inn! Vi setter oss i stua, der har vi allerede litt godteri og greier, det er jo Halloween i morra, vet du!

Når Maja Wilhelmsen ikke serverer smågodt til fremmede menn i hjemmet sitt, jobber hun som konstituert overlege ved Fysikalsk- og rehabiliteringsmedisinsk avdeling på

Universitetssykehuset Nord-Norge i Tromsø. Før hun begynte der kombinerte hun arbeid som allmennlege og doktorgradsstipendiat.

- Jeg synes det som er så interessant med rehabilitering er at man ser på menneskers funksjon i et større perspektiv. Den medisinske diagnosen har naturligvis sin plass i modellen, men det handler egentlig om hvordan pasientenes funksjon er, sett i lys av kroppslige funksjoner, hverdagslig aktivitet og sosial deltagelse, for eksempel i arbeid. For å gi god hjelp må man ta hensyn til komorbiditet, miljøfaktorer og ikke minst alle de ulike personlige faktorene folk har med seg. Du kan jo ha en pasient med Bekhterevs sykdom som blir ufør, og en annen som blir toppleder i NATO! Selve diagnosen er bare en liten del av historien, forklarer hun.

- Det høres temmelig omfattende ut?

- Jo, men det er da det er så utrolig tilfredsstillende å jobbe i tverrfaglige team. Man har så mye kompetanse lett tilgjengelig og kan konferere med andre, gjøre tilpasninger og gå mer i dybden på enkeltpasienter. Da jeg begynte, syntes jeg det var så herlig å slippe å sitte alene med alle avgjørelser hele tiden og heller samarbeide med flere om best mulig resultat. Som allmennlege er man så alene og må jobbe i et veldig høyt tempo. Men iblant savner jeg det også.

\section{Konsultasjonenes pris}

Ute på den store verandaen kjemper mennene i Majas liv mot snømassene. Det vil si: Far Thomas måker, mens Snorre (11) og Birk (8) ser ut til å være tildelt relativt frie roller. Et luktmolekyl fra godteskålen slipper gjennom vinduslisten og treffer åtteåringens bulbus olfactorius med et smell, han smetter innom og får med seg en bit.

- Så hva er det du savner med tiden som allmennlege?

- Det lange tidsforløpet er jo det fineste. For eksempel mannen som får hjerteinfarkt og etterpå blir så deprimert av frykten for å dø at han bare er et skall av seg selv, men som et år etterpå plutselig har klart å komme seg ovenpå igjen. Alle opp- og nedturene til alle disse menneskene, det er ganske unikt.

- Hva savner du minst?

- En ting jeg merket etter hvert var at når jeg var ferdig på jobb hadde jeg mistet helt lysten på å snakke med fremmede, enten det var tilfeldige på bussen eller når jeg var på fest. Jeg hadde hatt samtaler med så innmari mange mennesker i løpet av en arbeidsdag at jeg helst bare ville snakke vanlig med noen jeg kjente godt. At jeg er nysgjerrig på mennesker og glad i å bli kjent med nye folk, var jo litt av grunnen til at jeg ville bli lege, men det ble så mye av det på jobb at det nesten forsvant for meg privat. Det kom heldigvis tilbake, forsikrer hun fornøyd. 
Det er nesten vanskelig å tro at kvinnen som er så gnistrende til stede for meg nå, kunne bli så inderlig lei av fremmede. Men det er klart det koster, og det koster mest for den som investerer mest. Avkastningen er først og fremst pasientens.

Maja Wilhelmsen hadde ikke blitt mer folkefiendtlig enn at hun etter fire år med deltidsforskning tok med seg familien til Australia for å fullføre doktorgraden. Hun hadde lengtet tilbake.

\section{Blomstring}

- Jeg hadde en tante som flyttet til Melbourne da jeg var tre år. Da jeg var 14, bestemte jeg meg for å reise over og bo hos henne et halvt år, det var utrolig spennende. Jeg har nok alltid hatt en stor utfartstrang. Jeg elsker Nord-Norge og Troms $\varnothing$ - det er byen i mitt hjerte, men jeg må alltid ha en neste reise å planlegge. Nye steder, nye opplevelser, nye kulturer, det beriker livet for meg.

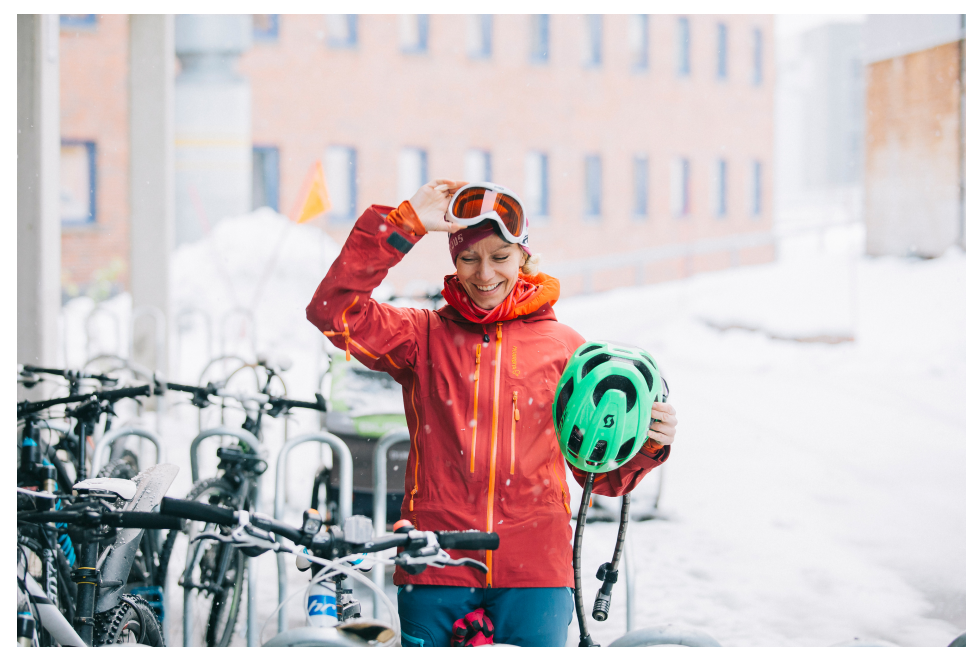

- Hvordan var det å være fjortis fra Tromsø i Melbourne da?

- De hadde skoleuniform, og noen elever røyket hasj nederst i skolegården, for å si det sånn, så ja - ganske annerledes. Og så var det en veldig fryktkultur i Australia som var helt ny for meg. Vi fikk aldri lov til å gå ut alene etter at det var blitt mørkt. Hjemme hadde vi jo mørketid, og det var helt utenkelig at man ikke skulle kunne være ute alene da!

- Forandret du deg i løpet av den tiden?

- Jeg har fått høre at jeg var veldig forsiktig på barneskolen, men da jeg kom på ungdomsskolen, ble jeg etter hvert mer selvsikker. Jeg vet ikke helt hva det handlet om, men det var jo en stor opplevelse å ha vært et halvår «alene» ute i verden. I hvert fall ble jeg mer utadvendt og var plutselig veldig engasjert i veldig mye som elevrådsleder, revysjef og leder for Operasjon dagsverk, forteller Wilhelmsen.

Etter ungdomsskolen ville hun egentlig begynne på tegning-, form- og fargelinje, men da satte foreldrene foten ned.

- Hvis jeg hadde lyst til å drive med kunst senere, ville de støtte meg fullt ut, men de ønsket at jeg skulle ta allmennfag og ha alle muligheter. Pappa har bare ungdomsskolen, og mamma gikk frisørlinjen, så det har ikke vært noen tradisjon for høyere utdanning i min familie.

Til tross for egne protester hadde ungjenta en slags vag tiltro til foreldrenes argumenter. De var nok glade for at de hadde tatt kampen, da datteren rundt 20 år senere disputerte med den første doktorgraden som er fullført ved Allmennmedisinsk forskningsenhet i Tromsø.

\section{Søppelsortering i nettjungelen}

På medisinstudiet følte hun seg dratt mot kirurgiens verden. Hun lot seg imponere og forføre av det forunderlige maskineriet som utgjorde menneskekroppen. Forestillingen om 
de usynlige nervetrådene som plutselig lå som en tykk kabel mellom fingrene hennes, det var fascinerende. En stund.

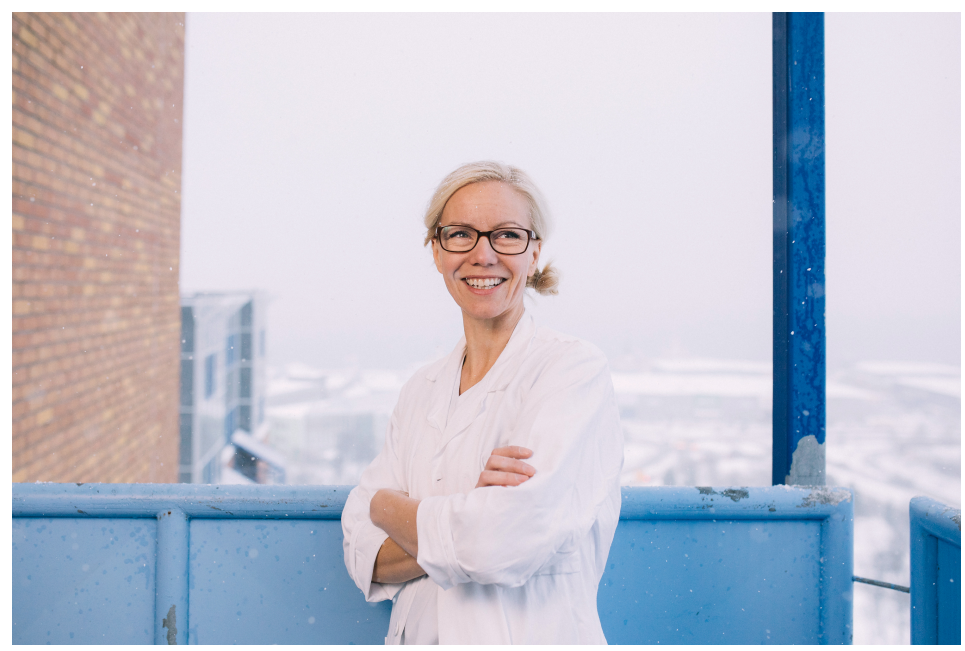

- Da jeg begynte å jobbe, ble jeg av en eller annen grunn mer tiltrukket av det vanlige enn det farlige. Jeg har forsket på depresjon og jobber nå med muskel- og skjelettplager. Det er store pasientgrupper, og mange er unge. De dør ikke, men de får ofte en massiv funksjonssvikt. Det å hjelpe folk til å leve bedre med en sykdom, slik at de kanskje klarer å stå i jobb, komme seg ut blant folk og ha stolthet i livet sitt, det synes jeg er givende, sier Wilhelmsen.

- Doktorgraden din handler om internettbasert kognitiv terapi. Hva går det egentlig ut på?

- Nettbasert informasjon og behandling kan være til stor hjelp for pasientene, men kan også være en stor byrde og kilde til bekymring. Det krever at vi som helsepersonell engasjerer oss i hvordan vi kan utnytte teknologien og bruke slike verktøy mer aktivt. Jeg forsket på depresjonsprogrammet MoodGym som støttebehandling til samtaleterapi. Vi sammenlignet intervensjonen med en kontrollgruppe som fikk «treatment as usual». Intervensjongruppen hadde bedre effekt både på psykisk symptomtrykk og tilfredshet med livet.

Det er en tett skog av deprimerte der ute, noen har det svart, resten har det mørkt. Dersom alle skal få psykologhjelp til å lysne tilværelsen, vil det kunne bli både dyrt og sykeliggjørende.

- Det er viktig å ha en trappetrinnsmodell hvor du kan tilby noe til de som plages litt, og henvise de som plages mye. Jeg tror generelt at internettbaserte intervensjoner kan være et veldig konkret og godt supplement til oppfølgingen hos fastlegen. Men det er selvfølgelig viktig at opplegget er forsket på og validert. Jeg så nylig en gjennomgang av 120 apper for ryggplager som var vurdert for layout, innhold og evidens - samtlige var søppel.

\section{Generelle råd hjelper ingenting}

Selv er Wilhelmsen ivrig på ny teknologi. Hun bruker mobilen til det meste og kontrollerer lydanlegget i stua via Sonos og lyset via Philips Hue.

- Jeg synes det er veldig artig. Se nå, jeg kan bare skru av alle lampene her ... sånn. Og så kan jeg sette dem på for eksempel «bright», eller den modulen vi har på nå som heter «relaxed».

Ifølge henne selv skal det også være en egen lysinnstilling som heter «disco» som hun begynner å knotte etter, men jeg forsikrer om at vi kan klare oss med «relaxed» i kveld. På verandaen har brøytepatruljen fyrt opp i bålgropa, til tross for at de for lengst har fått innendørs oppholdstillatelse.

- Men hvordan skal et dataprogram kunne erstatte leger i pasientbehandlingen?

- Jeg var i utgangspunktet skeptisk til internettbehandling, og jeg mener fortsatt at den medmenneskelige veilederrollen som fastlegene har, er uerstattelig. Men til syvende og sist 
er det jo pasienten selv som sitter igjen med ansvaret for egen helse. Da må vi kunne gi dem flere gode verktøy.

- At pasienter ikke tar nok ansvar for helsefremmende livsstilsendringer, er vel en ganske grunnleggende frustrasjon for mange leger - hva er det som skal til?

- Man vet i hvert fall at hvis man gir generelle råd, hjelper det ingenting. Vi må hjelpe den enkelte pasient til å finne ut hva som er de minste forandringene de kan gjøre i sitt liv, og begynne der. Om det er for å begynne å bevege på en vond rygg eller endre atferdsmønster som gir depresjon, tror jeg internettprogrammer kan hjelpe folk med å skape en struktur i endringsarbeidet som skal skje, sier Wilhelmsen med en smittende optimisme.

\section{Kjær i nord}

Optimisten overfor meg vil hjelpe mennesker til å leve bedre med plager de kanskje ikke blir kvitt. Jeg må tenke på det hvite viruset som angrep Tromsø samme dag - elsket på fjellet, hatet i byen. Tromsøværingene får ikke gjort så mye med det heller. Snøen forsvinner ikke, men man kan krumme nakken, måke bort litt og litt, banne hoderystende og halvsmilende med naboen, kjøpe Biltemas største isskrape og gjøre små tilpasninger slik at snøen etter hvert blir til å leve med.

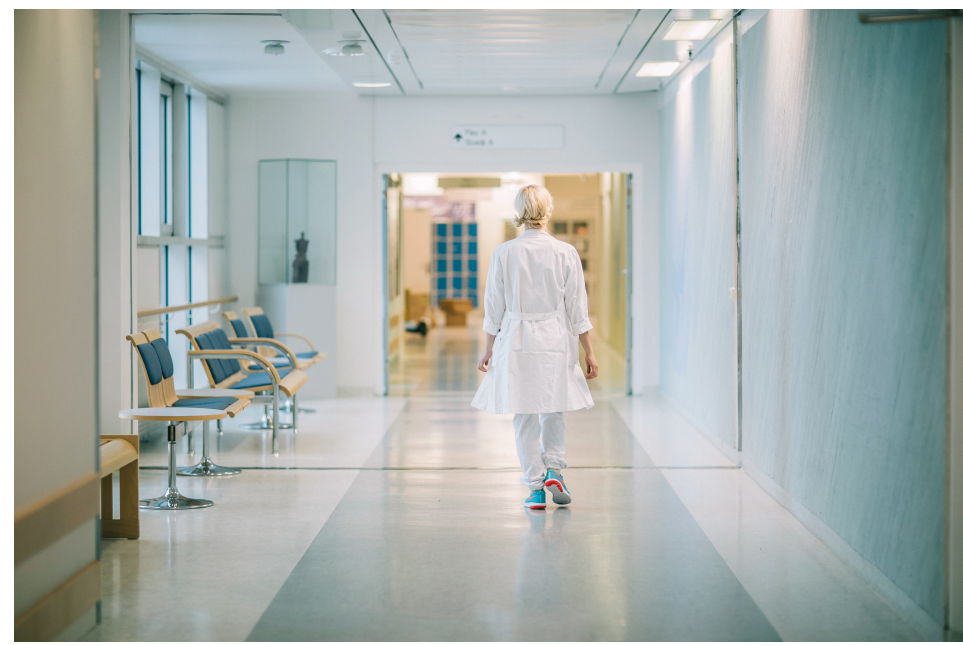

- Familien din ser ikke ut til å la seg bremse nevneverdig av den kommende vinteren, hva synes du egentlig om den?

- Selv om det var deilig å være i varmen i Australia, synes vi det var helt fantastisk å komme tilbake til Tromsø og snøen. Man kan jo bygge snømenn og snøborger, og nå som ungene er større kan vi gå på ski til fjelltoppene for å få luft i kinnene og utsikt over landskapet. Men jeg og Thomas er veldig klare på at vi ikke kunne bodd på landet, det skjer masse spennende i byen, og det vil vi benytte oss av.

- Dere er på filmfestival i januar da kanskje?

- Ja, jeg elsker TIFF, og vi er der hvert år. Vi bruker å ta en feriedag, få noen til å passe ungene og ha en skikkelig «kjærestedag». Vi ser da film, spiser lunsj, ser film, går ut og spiser med venner og ser kanskje enda en film til før vi fester litt videre utover natten, sier Wilhelmsen med et drømmende smil.

\section{Korridorens kjappeste}

Familielivet spinner mye rundt de to småguttene, som også krøkes tidlig til å bruke byen. Buktafestivalen på åpen lørdag, sushifeiringer på Rå og minikonserter på Backbeat. Birk har til og med vært nysgjerrig yngstemann på operaforestilling. På ferier er det barnas tur til å ta med mamma i berg-og-dal-bane. Det sies å være et av hennes favorittfremkomstmidler.

- Ungene gir hele livet et sunt perspektiv. Det er ikke så farlig med alt som ikke ble perfekt på jobb eller andre småting man kan irritere seg over, så lenge familien er frisk og har det 
godt.

- Hva slags ting kan du irritere deg over da?

- Tja ... det er ikke akkurat noen småting da, men jeg er medlem av Arbeiderpartiet. Noe som irriterte meg i valgkampen i høst, var at de ikke sa tydelig nei til oljeboring i Lofoten, Vesterålen og Senja. Det tror jeg var en tabbe, sier hun innbitt.

Men Wilhelmsen kan også irritere andre. Hun beskriver seg selv som handlekraftig, men det går ofte fort i svingene. En avdelingsleder på sykehuset synes det gikk såpass fort $\mathrm{i}$ korridorsvingene at hun nærmest grep tak i den flagrende frakken, tok henne til side og påpekte at tempoet hennes virket stressende på andre.

- Først tenkte jeg: «For ei drittkjerring som forteller meg at jeg ikke skal være effektiv!», men etter å ha tenkt meg om, skjønte jeg at hun hadde helt rett. Når man er for travel, får man ikke god kontakt med folk, og man gjør oftere feil. Så henne har jeg takket senere.

- Har du puttet dykkerlodd i arbeidsskoene nå da?

- Ja, nå går jeg faktisk saktere, ler den driftige tromsøpatrioten mens hun gjør seg klar til å dra på Hålogaland teater for å kapre billetter til vårprogrammet som slippes i kveld. Nok en gang klarer jeg å vekke japaneren til liv fra hypotermiens klør og transporterer billettjegeren trygt gjennom det forvandlede hvite landskapet ned til sentrum. Snart vinker vi til hverandre, og Maja Wilhelmsen forsvinner inn til varmen, lyset og latteren fra menneskene som nå er enda litt mer på lag enn ellers, nå som snøen laver ned utenfor. Men den lever de godt med.

Publisert: 22. januar 2018. Tidsskr Nor Legeforen. DOI:10.4045/tidsskr.17.1017

(C) Tidsskrift for Den norske legeforening 2020. Lastet ned fra tidsskriftet.no 